\section{Use of disposable prism tonometry in routine clinical practice}

SM Salvi ${ }^{1}$, S Sivakumar ${ }^{2}$ and SS Sidiki ${ }^{1}$

\begin{abstract}
Aim To establish the reliability, efficacy, and safety of disposable prism tonometry and validate its routine use for screening as well as monitoring of glaucoma.

Methodology Intraocular pressure (IOP) of 400 eyes of 200 consecutive patients who attended the general ophthalmic clinic was checked with both the Goldmann applanation tonometer and a disposable tonometer prism by an experienced examiner after obtaining informed consent. The data were statistically analysed.

Results The mean difference in the IOP between the two types of prisms was $0.1 \mathrm{mmHg}$ (SD $\pm 1 \mathrm{mmHg}$ ).

Conclusion Disposable prism tonometry provides a reliable, effective, and safe alternative to Goldmann reusable prism tonometry for routine screening as well as monitoring of glaucoma with the advantages of eliminating the need for chemical disinfection and therefore eliminating the risk of crossinfection.
\end{abstract}

Eye (2005) 19, 743-746. doi:10.1038/sj.eye.6701633; published online 10 September 2004

Keywords: intraocular pressure; disposable prism tonometry; Goldmann applanation tonometer; glaucoma screening; monitoring; single use

\section{Introduction}

Disposable prisms are being used instead of Goldmann reusable prisms for applanation tonometry at Ayr Hospital since April 2002. The ever-increasingly busy nature of the clinics made it difficult to ensure adequate disinfection of the Goldmann prism after each and every use. Hence, after discussion with the infection control department it was decided to move completely to disposable prism tonometry.
Tonosafe was chosen as an alternative to the Goldmann reusable prism. The product literature on Tonosafe disposable prism mentions, 'It is not intended that Tonosafe should replace the standard Goldmann prisms for quantitative clinical work, but is extremely suitable for screening and checking'. The study by Desai et $a l^{1}$ also supported the statement. A randomized clinical study was carried out to validate moving completely to disposable prism tonometry in routine clinical practice including screening and monitoring of glaucoma patients and also establish the reliability, efficacy, and safety of the disposable prism tonometry.

\section{Materials and methods}

\section{Patients}

Intraocular pressure (IOP) of 400 eyes of 200 patients was checked with both the Goldmann applanation tonometer (GAT) prism and the disposable tonometer prism (DTP) after obtaining informed consent. The study was conducted over a period of 1 month and the consecutive patients included were from the eye casualty, general, and specialists clinics including glaucoma clinics.

\section{The disposable prism}

The device (Tonosafe, Clement Clarke Inc.). consists of two parts:

- a precision moulded clear acrylic prism that slots into,

- the holder made of ABS material.

The combined mass of the holder and the prism is the same as the standard Goldmann prism $(1.65 \pm 0.05 \mathrm{~g})$. The prism is for single use, but the holder can be reused. Each pack consists of five trays, each of which in turn contain 20 disposable sterile prisms and one prism holder. The slot of the holder is aligned with the
${ }^{1}$ Department of Ophthalmology The Ayr Hospital, Ayr UK

${ }^{2}$ Department of Ophthalmology Birmingham Heartlands \& Solihull Hospital Birmingham, UK

Correspondence: SM Salvi Department of Ophthalmology Royal Gwent Hospital

Cardiff Road Newport NP20 2UB, UK Tel: + 441633238444 Fax: +44 1633656294

E-mail: karansalvi@aol.com

Received: 8 November 2003 Accepted: 13 April 2004

Published online:

10 September 2004

A poster based on this study titled 'One year of safe and effective use of disposable head applanation tonometry' won the Manchester Royal Eye Hospital Poster Prize at the Royal College of Ophthalmologists Annual Congress 2003. It was presented orally in an abridged form at the Glaucoma-Current opinion \& Practice Symposium organized by the Scottish Glaucoma Club at the Royal College of Surgeons, Edinburgh on 13th June 2003. Competing interest: The authors have no financial interest in any of the products mentioned. 
indexing key moulded into the prism and pushed firmly and the assembly is then inserted into the plunger of the tonometer in the conventional way.

\section{Methodology}

In the first 100 consecutive patients, the right eye was first checked by GAT followed by the disposable prism, while the left eye was first checked by disposable prism followed by GAT. The order was reversed to eliminate any error introduced by the first instrument. In the next 100 consecutive patients, the left eye was checked first with GAT followed by the DTP, while the right eye was checked by disposable prism followed by GAT. To eliminate bias, the tonometer dial was returned to $10 \mathrm{mmHg}$ position between two consecutive readings. Children, one-eyed patients, and patients with corneal scarring and high astigmatism were excluded from the study. Unlike GAT, the DTP does not have a red marking at $43^{\circ}$ to measure IOP in patients with high astigmatism.

\section{Results}

Table 1 compares the pressure measurements recorded by the two methods. The mean difference in the IOP between the two types of prisms was $0.1 \mathrm{mmHg}$ $(\mathrm{SD} \pm 1 \mathrm{mmHg}$ ) with the disposable prism reading being lower.

The data was analysed using the method described by Bland and Altman ${ }^{2}$ for assessing agreement between two methods of clinical measurement. Figure 1 shows the differences between the disposable prism and the Goldmann readings plotted against the average of the two readings. The middle horizontal line represents the mean difference $(0.1 \mathrm{mmHg})$ and the range of two standard deviations from the mean is shown by the dotted lines. The figure shows that the differences were scattered consistently; there is no suggestion that readings of very high IOP tend to be subject to any greater error than those of 'normal' IOP levels. In all, 95\% of readings fall between the two dotted lines, that is, between -2.1 and $+1.9 \mathrm{mmHg}$ (Figure 1 ).

\section{Discussion}

Inadequate disinfection of reusable prisms carries the risk of crosstransmission of bacterial and viral

Table 1 Comparison table

\begin{tabular}{lcccc}
\hline Applanating prism & $\begin{array}{c}\text { Number } \\
\text { of eyes }\end{array}$ & $\begin{array}{c}\text { Mean IOP } \\
(\mathrm{mmHg})\end{array}$ & $\begin{array}{c}\text { Standard } \\
\text { deviation }\end{array}$ & $\begin{array}{c}\text { Range } \\
(\mathrm{mmHg})\end{array}$ \\
\hline Disposable & 400 & 15.75 & 5.38 & $4-62$ \\
Goldmann & 400 & 15.85 & 5.38 & $4-60$ \\
\hline
\end{tabular}

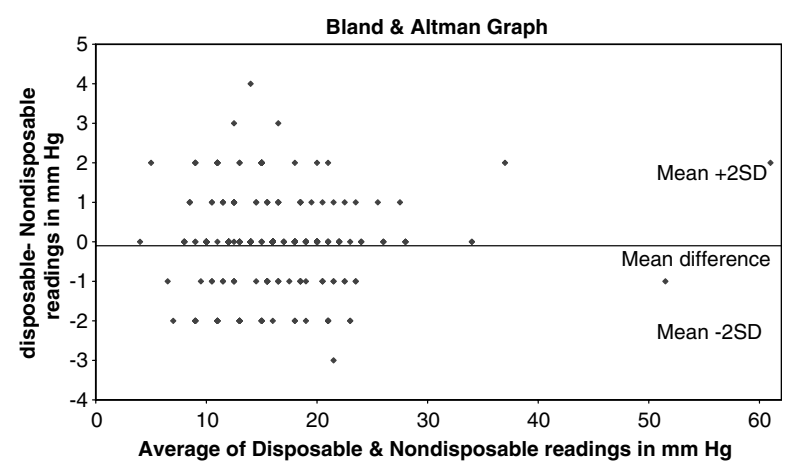

Figure 1 Bland and Altman plot showing good agreement of disposable prism tonometry with conventional Goldmann reusable prism tonometry.

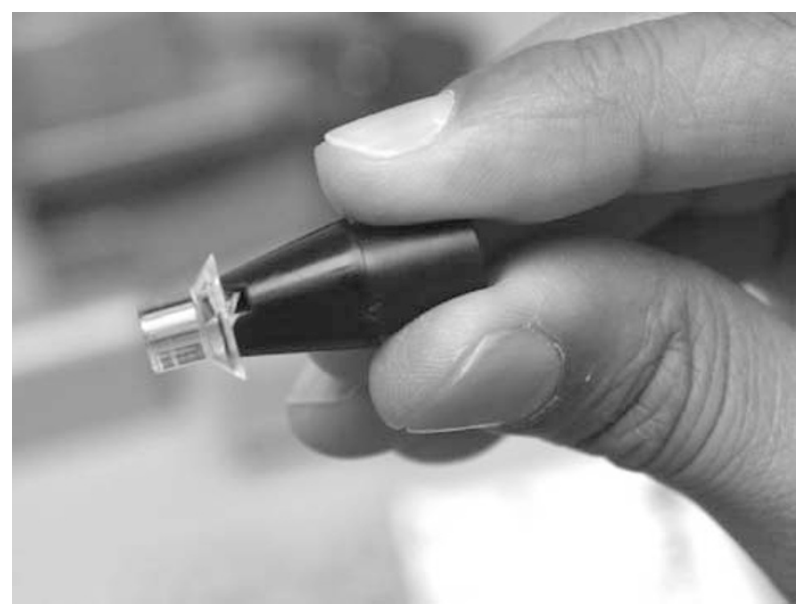

Figure 2 Disposable prism inserted into holder before the assembly is inserted on the plunger of the tonometer.

conjunctivitis. ${ }^{3}$ Risk of transmission of Hepatitis-C, HIV, $\mathrm{vCJD}$, acanthamoeba has also been speculated.

In a busy clinic setting, IOP of patients need to be checked at short intervals and it is difficult to ensure that the Goldmann prisms are disinfected for the recommended minimum of $10 \mathrm{~min}$ after every use. $\mathrm{MDA}^{4}$ has also published advice that components of ophthalmic devices that touch the surface of the eye should be restricted to single patient use wherever practicable and where this does not compromise clinical outcome. To eliminate any potential risk of crossinfection, DTPs were introduced at Ayr Hospital in April 2002.

This study was conducted to validate the routine use of disposable prism tonometry in all clinical patients, although the Tonosafe leaflet recommends its use for mainly screening purposes (Figure 2). In our study, disposable prism tonometry underestimated the value of Goldmann tonometry by just $0.1 \mathrm{mmHg}$. The 
measurements were reliable over the whole range of IOP measurements encountered in clinical practice. The study demonstrates the accuracy and reliability of disposable prism tonometry when compared to the gold standard of Goldmann tonometry. We believe the disposable prism can be used in routine clinical practice for quantitative clinical work, for screening as well as for monitoring of glaucoma in patients.

A questionnaire study was conducted after 1 year of use of disposable prisms to accumulate the experience of the users at Ayr Hospital. A simple multiple-choice questionnaire was answered by the 13 ophthalmologists and 10 nurses involved in measuring IOP with disposable prisms. Inferences from the study included a short learning curve $(21 / 23)$, ease of use $(22 / 23)$, and reproducible results $(23 / 23)$. Problems occasionally experienced were difficulty in inserting or removing assembly from some base units $(6 / 23)$, sharp edges sometimes causing pain to fingertips during removal of disposable prism (4/23), glare from prism edge $(3 / 23)$, increase in number of wipes required as widening of the mires due to lid touch $(2 / 23)$, and an isolated incident of corneal abrasion $(1 / 23)$. We feel from our experience that this new method of disposable tonometry is easy to learn, easy to use, and reliable.

The risk management department of the Medical Defence Union was contacted to find out if there have been any claims regarding transmission of eye infections via contaminated ophthalmology devices. Although there have been no claims directly implicating transmission of infection, there have been a handful of claims settled arising due to the patient suffering a chemical burn because the instrument was not adequately rinsed following disinfection. Certain agents of chemical disinfection of tonometer prisms like Sanichlor ${ }^{5}$ have also been associated with atopic dermatitis and asthma. With the disposable prism we had one reported incidence of corneal abrasion, but we feel that there is good circumstantial evidence that disposable tonometry is safe both to the patient and observer especially because it avoids problems like hypoclorite burns.

The main advantage of disposable prism is the complete elimination of any risk of crosstransmission of infection. Another advantage is the ease of use. As it comes in sterile packaging, it can be used and disposed as against the strict cleaning and disinfection required daily and in between patients for the Goldmann prism.

A structural deformity in some of the disposable prisms having implication on the accuracy has been reported. ${ }^{6}$ A similar problem was not encountered in our study. The main disadvantage of disposable prisms is the cost factor as explained in Table 2. Although not a
Table 2

\begin{tabular}{|c|c|}
\hline $\begin{array}{l}\text { Cost per } 100 \text { patients } \\
\text { Disposable prism } \\
\text { tonometry }\end{array}$ & $\begin{array}{l}\text { Goldmann prism } \\
\text { tonometry }\end{array}$ \\
\hline \multirow{2}{*}{$\begin{array}{l}100 \text { disposable } \\
\text { prism }=£ 62 /-\end{array}$} & One Goldmann prism: $£ 91 /-$ \\
\hline & $\begin{array}{l}\text { Milton and sterile water: } £ 5 /- \\
\text { Nurse time per day in preparing } \\
\text { solution in morning and cleaning } \\
\text { in evening: } 15 \text { min } \\
\text { Doctor/nurse time per day for } \\
\text { disinfection in between } \\
\text { patients: } 15 \text { min } \\
\text { Medicolegal cost if any } \\
\text { transmission of infection... }\end{array}$ \\
\hline
\end{tabular}

Cost per year

\begin{tabular}{ll}
\hline Disposable prism & Goldmann prism \\
\hline$£ 10,900 /$ - approximately & $£ 2110 /$ - approximately \\
\hline
\end{tabular}

formal analysis, we feel that our attempt to look at the cost issue gives an interesting insight into the cost $v$ s benefit ratio.

In all, 17580 patients attended the Ayr Hospital eye out-patients department in 1 year from April 2002 to March 2003 and it cost $£ 10900 /$ - to measure the IOP with disposable prisms. In the corresponding previous year, the cost incurred to measure IOP was $£ 910$ /- for replacing the 10 Goldmann prisms that were lost/ replaced and $£ 1200 /$ - towards the disinfection solution.

The disposable prism costs just around 62 pence (cost at Ayr Hospital). Although it adds to the cost of an out-patient consultation, it amounts only to the price of two units of single-use local anaesthetic eye-drops (British National Formulary, 46th edition, September 2003).

Owing to stricter infection control protocols, an increasing number of eye units in Scotland have changed their practice to the use of DTP. A telephonic survey was conducted and to the best of our knowledge at the time of the study, six ophthalmology units in Scotland were presently using DTPs. We believe that disposable prism tonometry may find an increasing role in IOP measurement in routine clinical practice in UK.

We conclude that disposable prism tonometry provides a reliable, effective, and safe alternative to Goldmann tonometry with the advantages of eliminating the need for chemical disinfection and eliminating the risk of crossinfection. It can be used not only for screening purposes but also for monitoring of glaucoma in routine clinical practice. 


\section{Acknowledgements}

We thank Dr Arvind Singh, Dr Ivan Hanna, and Dr Jeffrey Jay for their guidance, Sister Anne Kennedy and the staff at Ayr Hospital for participating in the questionnaire, Mr Robert Russell, Department of Statistics, University of Paisley, for Statistical assistance, and Sarah Syme, Medical Illustrations, Crosshouse Hospital, for the illustrations.

\section{References}

1 Desai SP, Sivakumar S, Fryers PT. Evaluation of a disposable prism for applanation tonometry. Eye 2001; 15: 279-282.

2 Bland J, Altman D. Statistical methods for assessing agreement between two methods of clinical measurement. Lancet 1986; i: 307-310.

3 Koo D, Bouvier B, Wesley M, Courtright P, Reingold A. Epidemic keratoconjunctivitis in a university medical center ophthalmology clinic: need for re-evaluation of the design and disinfection of instruments. Infect Control Hosp Epidemiol 1989; 10: 547-552.

4 Medical Devices Agency. MDA AN 1999(04).

5 Goverdhan S, Gaston H. Sanichlor-induced atopic dermatitis and asthma in ophthalmologists. Eye 2003; 17: 108-109.

6 Goel S, Chua C, Dong B, Butcher M, Ahfat F, Hindi SK et al. Comparison between standard Goldmann applanation prism and disposable applanation prism in tonometry. Eye 2004; 18: 175-178. 